\title{
PREDIKSI NILAI KUAT TEKAN UNIAKSIAL BATUAN PENGAPIT BATUBARA MENGGUNAKAN DATA ULTRASONIK DI KABUPATEN MUSI BANYUASIN SUMATERA SELATAN
}

\author{
Prediction of Uniaxial Compression Strength Values of Rocks \\ Flanking Coal Using Ultrasonic Data at Musi Banyuasin Regency - \\ South Sumatera
}

\author{
ZULFAHMI ${ }^{1}$, ILDREM SJAFRI ${ }^{2}$, ABDURROKHIM ${ }^{2}$ dan RIDHO K. WATTIMENA ${ }^{3}$ \\ 1. Puslitbang Teknologi Mineral dan Batubara \\ Jalan Jenderal Sudirman 623 Bandung 40211 \\ Telp. (022) 6030483, Fax. (022) 6003373 \\ e-mail: zulfahmi@tekmira.esdm.go.id \\ 2. Fakultas Teknik Geologi - Universitas Padjadjaran \\ Jalan Raya Bandung Sumedang KM 21, Jatinangor 45363 \\ 3. Fakultas Teknik Pertambangan dan Perminyakan - Institut Teknologi Bandung \\ Jalan Ganesha No. 10 Bandung 40132
}

\begin{abstract}
ABSTRAK
Dukungan data geomekanika sangat dibutuhkan dalam merancang gasifier, analisis dan pemodelan pada gasifikasi batubara bawah tanah (underground coal gasification-UCG), baik yang berasal dari uji langsung (in-situ) maupun uji laboratorium. Salah satu data pengujian laboratorium yang cukup penting untuk mengevaluasi kondisi batuan di lokasi UCG adalah uji kuat tekan uniaksial (uniaxial compressive strength test-UCS). Uji ini membutuhkan dimensi percontoh spesifik yang tidak digunakan untuk uji laboratorium lain seperti uji geser langsung, triaksial atau brazzilian. Karena itu, untuk optimalisasi pengujian percontoh harus dipilih secara selektif karena untuk mendapatkan percontoh dari pemboran inti sangat sulit, memakan waktu dan sangat mahal. Salah satu cara untuk mengoptimalkan pemanfaatan percontoh adalah dengan melakukan korelasi dengan hasil uji lain yang memiliki output yang sama. Pada penelitian ini telah dilakukan korelasi antara uji UCS yang bersifat merusak (destructive) dengan uji ultrasonik yang bersifat tidak merusak (non-destructive), relatif murah, cepat, mudah dan percontoh dapat digunakan lagi untuk uji yang lain. Sebanyak 89 uji UCS dan ultrasonik telah dilakukan untuk memperoleh tiga korelasi empiris nilai UCS dan ultrasonik yang berasal dari percontoh batuan pengapit batubara (batu lempung, batu lanau dan batu pasir). Korelasi ini dapat digunakan untuk memprediksi nilai UCS secara empiris di lokasi telitian yaitu di desa Macang Sakti, Kecamatan Sangadesa, Kabupaten Musi Banyuasin, Propoinsi Sumatera Selatan. Korelasi tersebut dihasilkan dari persamaan polinomial orde 2 dan 3. Untuk batu lempung nilai $\sigma_{c}$ dapat diperoleh dari $U_{C} S_{c l s}=\left(2 \times 10^{-10}\right) V^{3}-\left(5 \times 10^{-6}\right) V_{p}{ }^{2}+0,0404 V_{p}-20,986$ dengan nilai $R^{2}=0,9087$. Untuk batu lanau nilai $\sigma_{c}$ dapat diperoleh $U C S_{\text {sis }}=\left(3 \times 10^{-6}\right) V_{p}{ }^{2}+0,0051 V_{p}+9,8665$ dengan nilai $R^{2}=0,8953$ dan nilai $\sigma_{c}$ batu pasir dapat diperoleh dari $U C S_{\text {sas }}=-\left(7 \times 10^{-7}\right) V_{p}^{2}+0,0467 V_{p}-$ 41,484 dengan nilai $R^{2}=0,8864$.
\end{abstract}

Kata kunci : UCS, ultrasonik, korelasi empiris. 


\begin{abstract}
Support of geomechanics parameters is needed for gasifier design, analysis, and modeling on underground coal gasification (UCG) both from in-situ and laboratory test. One important of a laboratory test to evaluate of rock condition at UCG location is uniaxial compressive strength test (UCS). This test needs the specific dimension sample and also the sample that does not use for another laboratory test after testing such as for direct shear, triaxial or Brazilian test. To optimize the test, the sample should be chosen selectively. To get the sample by core drilling is very difficult, time-consuming and costly. One way to optimize the use of samples is by using correlation with another test that has the same output. This study has been conducted by the correlation between UCS and ultrasonic tests. UCS test is the destructive test and the ultrasonic test is non-destructive, relatively inexpensive, fast, easy to conduct and the samples can be re-used for another test. A total of 89 ultrasonic and uniaxial compressive strength tests were conducted to establish three empirical correlation of UCS and a sonic velocity from the rocks flanking coal ( claystone, sandstone, and siltstone). This correlation can be used to predict the value of UCS empirically on research location at Macang Sakti, District of Musi Banyuasin, South Sumatra Province. The correlations resulted from the polynomial equation of ordo 2 and 3. To Claystone $\sigma_{c}$ value can be obtained from $U C S_{c l s}=\left(2 \times 10^{-10}\right) V p^{3}-\left(5 \times 10^{-6}\right) V_{p}^{2}+0,0404 V_{p}-20,986$ with $R^{2}=0.9087$. To siltstone $\sigma_{c}$ value can be obtained $U C S_{s i s}=\left(3 \times 10^{-6}\right) V_{p}^{2}+0,0051 V_{p}+9,8665$ with $R^{2}=0.8953$ and $\sigma_{c}$ Sandstone value can be obtained from UCS sas $=-\left(7 \times 10^{-7}\right) V_{p}^{2}+0,0467 V_{p}-41,484$ with $R^{2}=0.8864$.
\end{abstract}

Keywords: UCS, ultrasonic, empirical correlation

\section{PENDAHULUAN}

Ketergantungan Indonesia terhadap impor energi semakin tinggi akibat meningkatnya permintaan dan menurunnya produksi minyak bumi dan gas (migas) dalam negeri. Impor minyak Indonesia diperkirakan akan terus tumbuh hingga 4 kali lipat pada kurun waktu 20112030 (Sugiyono dkk., 2013). Demikian juga bahan bakar gas, Indonesia telah mengimpor sebagian besar LPG dan akan mulai mengimpor gas alam setelah tahun 2020 (Asian Pacific Economy Cooperation, 2013). Untuk negara-negara dengan cadangan minyak dan gas bumi yang relatif sedikit seperti Indonesia tetapi mempunyai cadangan batubara yang cukup banyak, gasifikasi batubara dapat menjadi alternatif pemecahan permasalahan energi pengganti di masa mendatang. Sekitar 161 miliar ton sumber daya batubara ada di Indonesia dan dengan cadangan sebesar 28,17 miliar ton (Pusat Sumber Daya Geologi, 2012) sangat menjanjikan. Gasifikasi batubara dapat dilakukan di dalam tanah (Underground Coal Gasification/UCG). Investasi yang dibutuhkan lebih murah dibandingkan gasifikasi batubara di permukaan. Menurut Bayrack (2015), teknologi UCG memiliki beberapa keunggulan dibandingkan coalbed methane (CBM), namun penerapan teknologinya sangat bergantung pada kondisi lingkungan permukaan dan bawah permukaan yang mendukung untuk proses gasifikasi tersebut. Dukungan data geomekanika sangat dibutuhkan dalam merancang gasifier untuk UCG, baik yang berasal dari uji langsung (insitu) maupun uji laboratorium.

Untuk memperoleh data yang berasal dari uji laboratorium diperlukan percontoh yang berasal dari inti bor. Keterbatasan akan peralatan, waktu dan anggaran menyebabkan percontoh hasil pemboran tidak cukup untuk memperoleh data yang sesuai dengan kebutuhan, sehingga seringkali hasil yang diperoleh kurang optimal. Salah satu pengujian yang cukup penting untuk mengevaluasi kondisi batuan di lokasi UCG adalah uji kuat tekan uniaksial atau unaxial compressive strength (UCS). Uji ini berdasarkan SNI 2825 : 2008, BSN (2008) yang membutuhkan dimensi percontoh yang sesuai dengan standar pengujian, yaitu panjang percontoh minimal dua kali diameter percontoh tersebut. Beberapa peneliti seperti Karaman dkk. (2015), Kabilan dkk. (2016) dan Yurdakul, dkk. (2011), menggunakan dimensi percontoh dengan panjang lebih dari dua kali diameter. Dengan adanya persyaratan tersebut, seringkali dalam melakukan uji UCS, pengujian penting lainnya tidak dapat diuji karena keterbatasan percontoh. Terlebih lagi uji UCS ini bersifat destructive, sehingga percontoh yang telah diuji tidak dapat digunakan lagi untuk pengujian yang lain. Salah satu pengujian laboratorium yang bersifat tidak merusak (non-destructive) namun menghasilkan parameter yang serupa dengan UCS adalah ultrasonik. Pengujian ini dilakukan dengan menilai kecepatan rambat gelombang. Uji ini lebih dikenal dengan istilah Ultrasonic 
Pulse Velocity Test, dilakukan dengan standar nasional Indonesia (SNI 03-2485-1991), BSN (1991) menggunakan alat PUNDIT (portable unit non-destructive digital indicated tester).

Parameter yang dihasilkan dari pengujian ini adalah nilai modulus elastisitas, modulus bulk, konstanta lame dan poisson ratio. Dasar pengukuran dilakukan dengan menghitung waktu tempuh gelombang primer dan sekunder yang merambat melalui percontoh batuan. Kelebihan metode ini tidak merusak percontoh (nondestructive) sehingga percontoh yang telah diuji dapat digunakan untuk pengujian yang lain.

Beberapa peneliti sebelumnya telah melakukan korelasi terhadap dua pengujian ini antara lain oleh McNally, (1987), Horsrud (2001), Barton (2002), Chang dkk. (2006), Martinez-Martinez dkk. (2006), Ali (2008), Lai dkk. (2014), Briševac dkk. (2015), Rao, dkk. (2016) dan Lai dkk. (2016).

McNally (1987) melakukan uji korelasi terhadap batu pasir yang terkonsolidasi dan tak terkonsolidasi untuk mengetahui nilai UCS berdasarkan waktu tempuh gelombang $\mathrm{P}\left(\mathrm{t}_{\mathrm{p}}\right)$. Horsrud (2001) melakukan uji korelasi untuk memprediksi UCS dari kecepatan waktu tempuh gelombang ultrasonik untuk batuan serpih tersier yang mempunyai porositas tinggi yang berasal dari laut utara (North Sea Region). Barton (2002) menjelaskan dalam sistem Q (Qsystem) yang dikembangkannya bahwa terdapat korelasi antara UCS dengan kecepatan seismik, dimana nilai $V_{p} \approx 3,5+\log Q_{c}$. Nilai $V_{p}$ adalah kecepatan rambat gelombang primer dari hasil uji ultrasonik atau uji sesimik $(\mathrm{km} / \mathrm{det})$ dan nilai $\mathrm{Qc}_{\mathrm{c}}$ adalah nilai empiris dari $\mathrm{Q}$ (rock mass quality rating) yang berasal dari nilai kuat tekan atau UCS (km/det). Martinez-Martinez $d k k$. (2006) melakukan penelitian terhadap tiga batuan sedimen untuk material bangunan dengan melakukan korelasi antara uji ultrasonik dan UCS menggunakan analisis multivariate. Ali (2008) melakukan uji terhadap kekuatan beton. (Briševac dkk. (2015) membuat model untuk mengestimasi nilai UCS dan modulus elastisitas menggunakan beberapa variasi pengujian termasuk uji ultrasonik. Sedangkan Lai $d k k$. (2016) melakukan penelitian untuk mengetahui hubungan empiris antara nilai UCS dengan nilai ultrasonik berupa nilai waktu tempuh gelombang primer pada batuan granit dan skis.
Uji UCS dan ultrasonik telah dilakukan terhadap tiga jenis batuan pengapit batubara (carbonaferous rock) yang berada di lokasi telitian di desa Macang sakti, Kecamatan Sangadesa, Kabupaten Musi Banyuasin Propinsi Sumatera Selatan. Tiga jenis batuan tersebut adalah batu lempung, batu lanau dan batu pasir. Pemilihan tiga jenis batuan ini didasari oleh dominannya batuan tersebut sebagai batuan pengapit batubara di lokasi telitian.

Tujuan dari penelitian ini adalah untuk mengetahui korelasi antara nilai kuat tekan ketiga batuan tersebut dengan nilai yang ditampilkan berdasarkan uji ultrasonik. Manfaatnya adalah untuk mengestimasi secara empiris nilai UCS berdasarkan hasil uji ultrasonik, sehingga penggunaan percontoh untuk uji laboratorium dapat lebih optimal.

\section{LOKASI DAN KONDISI GEOLOGI}

Secara geografis daerah telitian terletak di $2^{\circ}$ $35^{\prime} 00,05^{\prime \prime}-2^{\circ} 33^{\prime} 45,38^{\prime \prime}$ LS dan $103^{\circ} 22^{\prime}$ $10,12^{\prime \prime}-103^{\circ} 22^{\prime}$ 55,16" BT (Gambar 1) sekitar $200 \mathrm{~km}$ dari kota Palembang. Lokasi berada dalam wilayah PKP2B PT. Astaka Dodol. Kegiatan pemboran telah dilakukan sebanyak 15 titik, sebagian diambil inti bornya dan sebagian lagi dilakukan pemboran non inti. Secara litologi percontoh diambil secara acak dari berbagai kedalaman seperti diperlihatkan pada Gambar 2.

Wilayah telitian mencakup tiga Formasi yaitu Formasi Air Benakat, Formasi Muara Enim dan Formasi Kasai (Tabel 1). Formasi Air Benakat; berumur Miosen Tengah sampai awal Miosen Atas. Arah umum jurus pada Formasi ini adalah Barat Laut - Tenggara dengan kemiringan berkisar $20^{\circ}-40^{\circ}$. Formasi ini secara litologis didominasi oleh batulempung abu-abu gelap kebiruan sampai abu-abu gelap kecoklatan, setempat tufaan, lunak dan getas di bagian bawah; di bagian tengah tersusun oleh batupasir halus-sedang, glaukonit, hijau muda-abu-abu kecoklatan mengandung kuarsa, feldspar dan fragmen batuan lain; di bagian atas tersusun oleh perselingan batu pasir, batu lempung, batu lanau dan serpih dengan sisipan tipis pasir kuarsa. Satuan batuan ini terbentuk pada fasa regresi, bersifat endapan laut dangkal. Di daerah penyelidikan pada Formasi ini tidak dijumpai batubara. 
Formasi Muara Enim; Formasi ini pembawa batubara yang diendapkan selaras di atas Formasi Air Benakat dengan tebal $200-800$ meter, berumur Miosen Atas - Pliosen Bawah. Formasi ini diendapkan sebagai kelanjutan dari fasa regresi. Berdasarkan kelompok kandungan lapisan batubara, formasi ini dapat dibagi menjadi empat anggota yaitu M1, M2, M3 dan M4 (Minjbouw, 1978). Anggota M1 merupakan perulangan batu pasir, batu lanau, batu lempung dengan sisipan batu bara. Batu pasir berwarna abu-abu sampai abu-abu kecoklatan, berbutir halus hingga sedang, kompak, terpilah baik, dengan fragmen kuarsa dominan.

Perselingan batu lempung dan batu pasir, berwarna abu-abu, terdapat nodul-nodul gamping, coklat terang, keras. Sedangkan batu lanau berwarna abu-abu, kompak, umumnya berselingan dengan batu lempung. Batu bara dijumpai dua lapisan dengan ketebalan antara 0,5 sampai $1 \mathrm{~m}$. Anggota M2 terdiri atas batu lempung, batu lempung karbonan, batu pasir, batu lanau dan batu bara. Batu lempung umumnya berwarna abu-abu gelap, masif, sering ditemukan struktur sedimen laminasi paralel, jejak tumbuhan serta fragmen batu bara. Batu lempung karbonan, berwarna abuabu kecoklatan, umumnya agak lunak dan biasanya bertindak sebagai batuan pengapit batubara. Batu pasir berwarna abu-abu terang sampai abu-abu kehijauan, berbutir halus sampai sedang, membulat sedang, terpilah buruk, mudah terurai, fragmen kuarsa dominan. Batu lanau berwarna abu-abu kehijauan hingga abu-abu kecoklatan, kompak, umumnya ditemukan struktur sedimen laminasi paralel. Batu bara yang ditemukan pada anggota M2 ini berjumlah tiga lapisan dengan tebal antara 0,3 sampai 6,6 m. Anggota M3 terdiri atas batu pasir, batu lanau, batu lempung, dan batu bara. Batu pasir berwarna abu-abu, berbutir halus, terpilah baik, mineral kuarsa dominan. Batu lanau, abu-abu terang kehijauan sampai kecoklatan, kompak, struktur sedimen laminasi paralel, mengandung jejak tumbuhan. Batu lempung berwarna abu-abu kecoklatan, kompak, masif, banyak dijumpai jejak tumbuhan. Batu bara ditemukan dua lapisan tebal 1,0 sampai 8,1 m. Anggota M4 terdiri atas batu pasir, batu lanau, batu lempung, dan batu bara. Batu pasir berwarna abu-abu terang, berbutir halus, terpilah baik, tufaan dan mineral kuarsa banyak dijumpai. Batu lanau, abu-abu terang, kompak, mengandung jejak tumbuhan, struktur tumbuhan, struktur sedimen laminasi paralel. Batu lempung berwarna abu-abu kecoklatan, lunak, kompak, struktur sedimen laminasi, pararel dan jejak tumbuhan banyak ditemukan. Batubara pada anggota M4 ditemukan dua lapisan dengan ketebalan berkisar antara 1,0 sampai $3,7 \mathrm{~m}$.

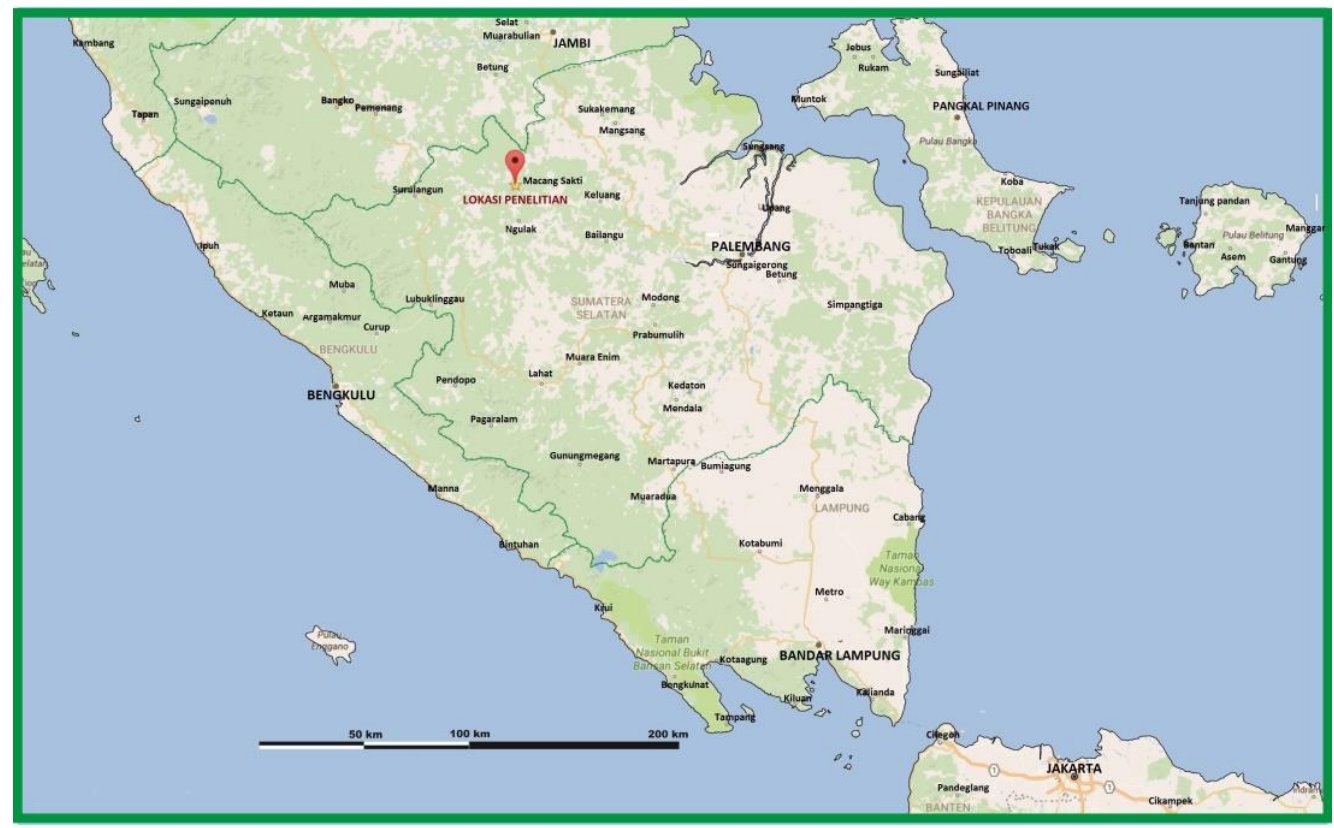

Gambar 1. Lokasi penelitian 


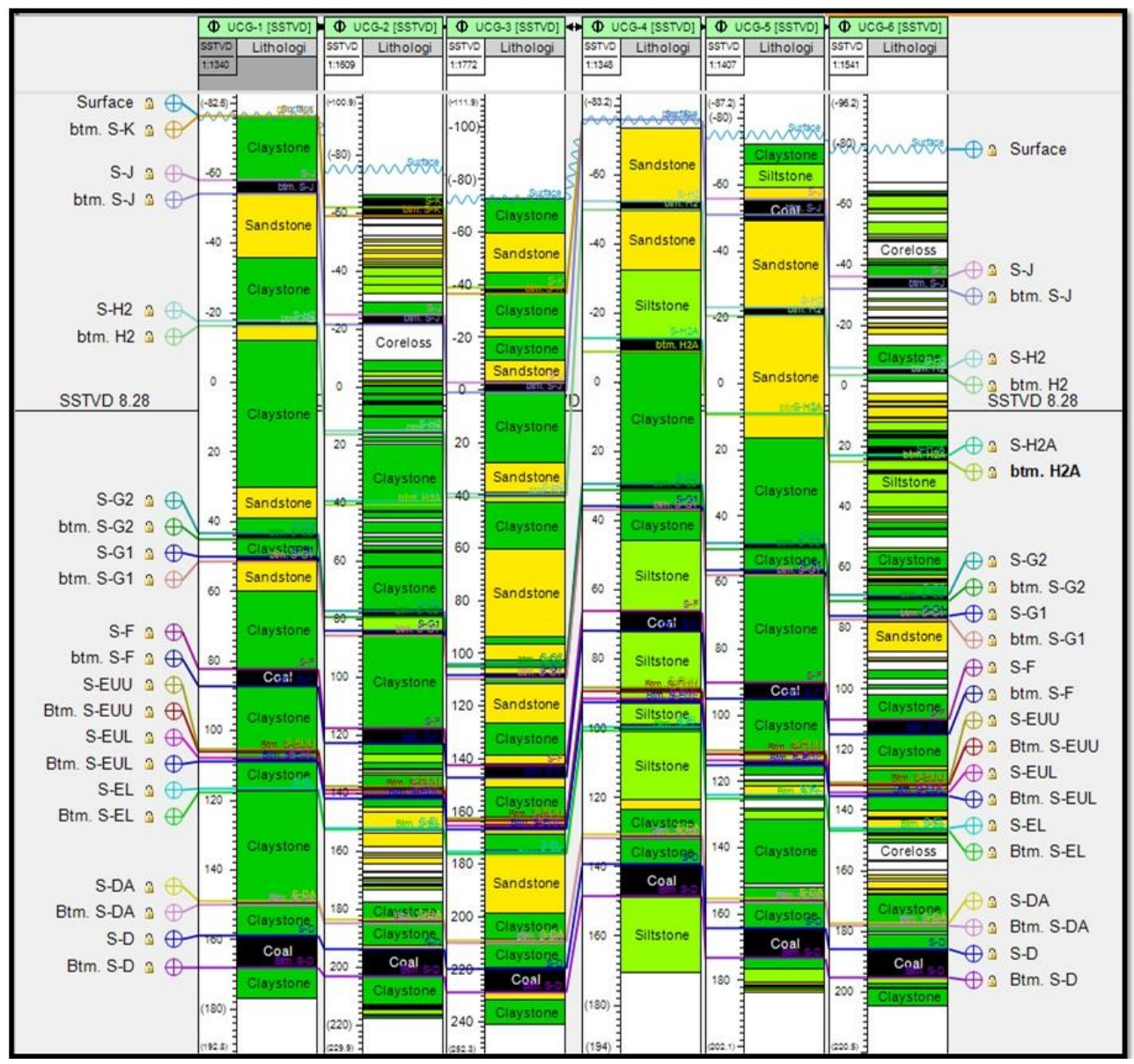

Gambar 2. Kondisi litologi di lokasi pengambilan percontoh

Formasi Kasai; terendapkan di atas Formasi Muara Enim yang berumur Pliosen, tersusun dari batulempung tufaan biru kehijauan dan biru, batupasir tufaan hijau, batuapung sedangkan endapan aluvial; terdiri atas kerakal, kerikil, batupasir halus-kasar, lepas-lepas. Secara lokal, kenampakan struktur di wilayah penyelidikan merupakan hasil dari gaya tegasan utama yaitu gaya kompresif berarah Barat Laut - Timur Laut, yang menghasilkan pola struktur lipatan regional antiklinorium dan sinklinorium yang bersumbu Barat Laut Tenggara. Di beberapa tempat akibat tegasan tersebut mengakibatkan terjadinya pensesaran baik sesar geser maupun sesar normal.

\section{METODOLOGI}

Setelah dilakukan preparasi dan mengukur dimensi percontoh, dilakukan uji yang tidak merusak (non-destructive) yaitu uji ultrasonik. Selanjutnya dilakukan uji UCS yang merusak percontoh (destructive). Percontoh yang digunakan sebanyak 89 buah, terdiri atas batulempung, batulanau dan batupasir.

Uji kecepatan rambat gelombang ultrasonik dilakukan untuk menentukan cepat rambat gelombang ultrasonik yang merambat melalui contoh batuan. Pada uji ini, waktu tempuh gelombang primer dan sekunder diukur dengan menggunakan Portable Unit Nondestructive Digital Indicated Tester (PUNDIT) (Gambar 3.b). Kecepatan rambat gelombang primer menjadi parameter korelasi untuk uji ultrasonik dan diperoleh dari persamaan :

$$
V_{p}=\frac{L_{b}}{t_{b}}
$$

Keterangan:

$\mathrm{Lb}=$ panjang contoh batuan yang diuji (m)

$\mathrm{t}_{\mathrm{p}}=$ waktu tempuh gelombang primer (detik)

$\mathrm{V}_{\mathrm{p}}=$ kecepatan rambat gelombang primer (meter/detik) 
Tabel 1. Stratigrafi regional cekungan Sumatera Selatan

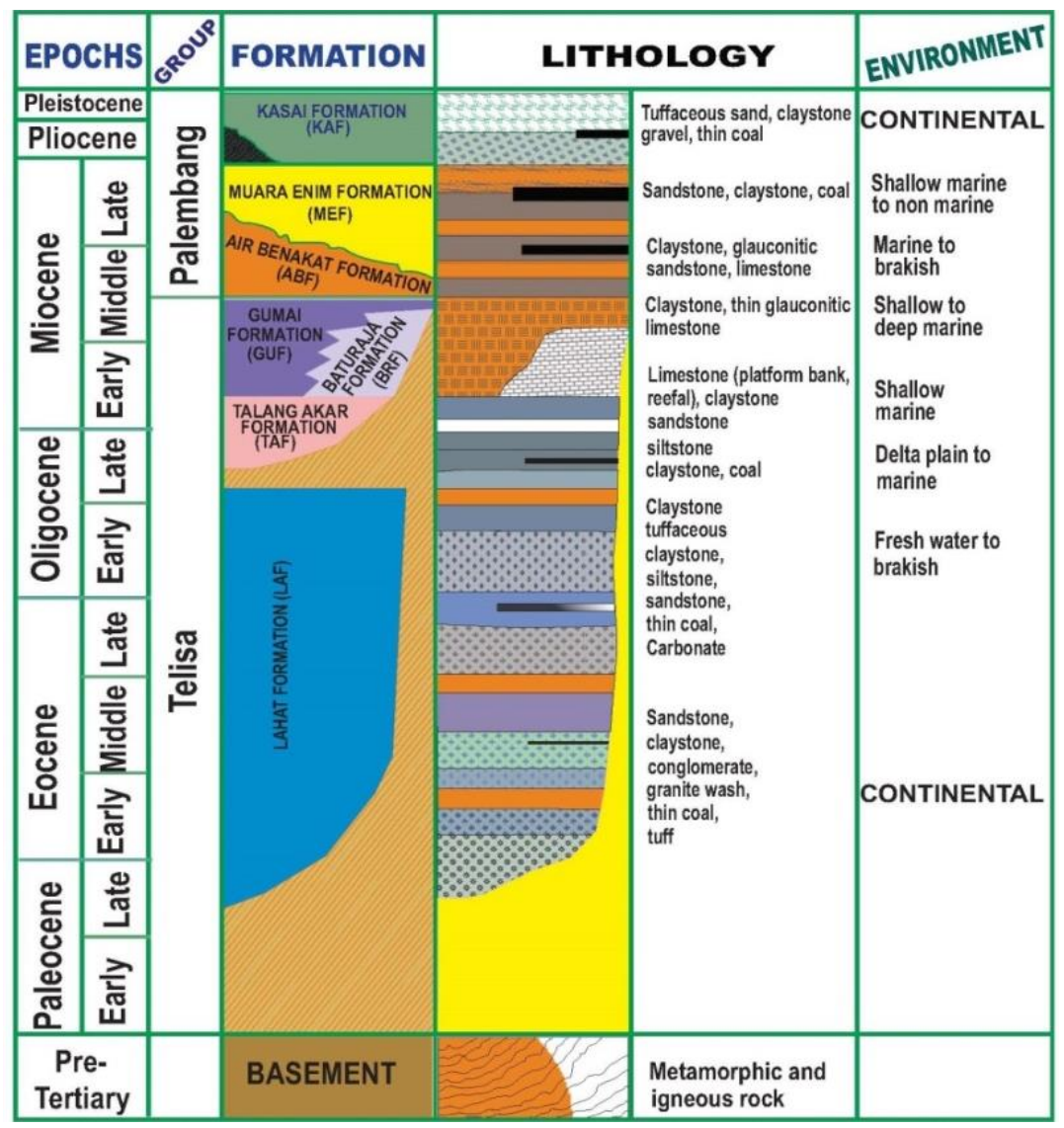

Sumber : De Coster (1974), hasil modifikasi

Cepat rambat gelombang ini dipengaruhi oleh beberapa faktor yaitu: ukuran butir dan bobot isi, porositas dan kandungan air, temperatur dan bidang lemah. Batuan yang memiliki ukuran butir halus, cepat rambat gelombang akan lebih besar daripada batuan yang berukuran kasar, karena batuan berbutir kasar akan memberikan ruang kosong antar butir lebih besar dibandingkan yang berbutir halus. Ruang kosong inilah yang menyebabkan cepat rambat gelombang menurun karena tidak ada media perambatannya. Sebaliknya batuan yang berbutir halus memiliki bobot isi lebih padat dibandingkan dengan batuan yang berbutir kasar, sehingga akan memiliki cepat rambat gelombang yang tinggi.

Porositas dan kandungan air juga mempengaruhi cepat rambat gelombang pada batuan tertentu. Semakin tinggi nilai porositas semakin banyak rongga atau ruang kosong di dalam batuan. Sehingga semakin tinggi porositas maka cepat rambat gelombang akan semakin kecil. Kandungan air dalam batuan yang cenderung berpori akan merubah kecepatan rambat gelombang di dalam batuan tersebut. Kecepatan rambat gelombang akan bertambah besar bila terjadi peningkatan derajat kejenuhan air pada porositas tertentu. Hal ini terjadi karena kecepatan rambat gelombang di dalam air jauh lebih besar dibandingkan dengan kecepatan rambat gelombang di udara.

Selain itu secara teoritis pengaruh temperatur akan merubah kondisi dan struktur percontoh sehingga kecepatan rambat gelombang ultrasonik juga dipengaruhi. Perubahan temperatur secara tak langsung juga dapat mempengaruhi cepat rambat gelombang yang merambat melalui percontoh batuan, karena dapat merubah sifat fisika dari batuan itu sendiri, terutama munculnya fisure atau fracture yang mencirikan terbentuknya bidang lemah yang berada di dalam batuan. Kehadiran bidang lemah ini akan menurunkan cepat rambat gelombang.

Uji kuat tekan uniaksial dilakukan dengan alat uji kuat tekan (Gambar 3.a) untuk menentukan 
nilai kuat tekan batuan ( $\sigma \mathrm{t}$ ) dan kurva tegangan-regangan. Dari kurva tegangan-regangan akan diperoleh nilai Modulus Elastisitas (E), Modulus Geser (G), Modulus Ruah (K), Nisbah Poisson (v) dan Konstanta Lame. Percontoh batuan berbentuk silinder ditekan atau dibebani sampai runtuh. Perbandingan antara tinggi dan diameter (D) percontoh silinder yang umum digunakan adalah 2D - 2,5D. Nilai tegangan pada saat percontoh batuan hancur didefinisikan sebagai kuat tekan uniaksial batuan dan diberikan oleh hubungan:

$$
\sigma_{c}=F / A
$$

Keterangan:

$\sigma_{\mathrm{C}}=$ Kuat tekan uniaksial batuan (MPa)

$\mathrm{F}$ = Gaya yang bekerja pada saat contoh batuan hancur $(\mathrm{kN})$

$\mathrm{A}=$ Luas penampang awal contoh batuan yang tegak lurus arah gaya $\left(\mathrm{cm}^{2}\right)$

Akumulasi kondisi batuan (sifat fisik dan mekanik) juga akan sama seperti pengujian dengan ultrasonik, yaitu dapat mempengaruhi nilai uji UCS. Kesamaan parameter yang diuji ini menjadi dasar untuk melakukan korelasi empiris antara uji UCS dan Ultrasonik.

\section{HASIL DAN PEMBAHASAN}

Ada tiga korelasi yang telah dilakukan dalam penelitian ini, yaitu korelasi antara uji UCS dengan Ultrasonik pada batu lempung, batu lanau dan batu pasir. Pada tulisan ini korelasi yang digunakan adalah antara nilai kuat tekan $(\sigma c)$ dengan nilai cepat rambat gelombang primer. Kedua parameter ini dipilih karena langsung diukur pada saat pengujian, sedangkan nilai yang lain seperti nilai Modulus Elastisitas (E), Modulus Geser (G), Modulus Ruah (K), Nisbah Poisson (v) dan Konstanta Lame dapat diperoleh dari perhitungan kurva tegangan regangan (uji UCS) dengan persamaan berikut :

$G=\rho \cdot V_{s}^{2}$

$\mathrm{u}=\frac{\left\{1-2\left(\frac{v_{\mathrm{s}}}{v_{p}}\right)^{2}\right\}}{2\left\{1-\left(\frac{v_{s}}{v_{p}}\right)^{2}\right\}}$

$E=2(1+u) G$

$K=(\rho / 3)\left(3 v_{p}^{2}-4 v_{s}^{2}\right)$

Keterangan :

$\rho=$ massa persatuan volume

$\mathrm{V}_{\mathrm{p}}=$ cepat rambat gelombang primer

$\mathrm{V}_{\mathrm{s}}=$ cepat rambat gelombang sekunder

Hasil pengujian dan perhitungan untuk nilai UCS dan ultrasonik untuk masing-masing batuan diperlihatkan pada Tabel 2, 3 dan 4 .

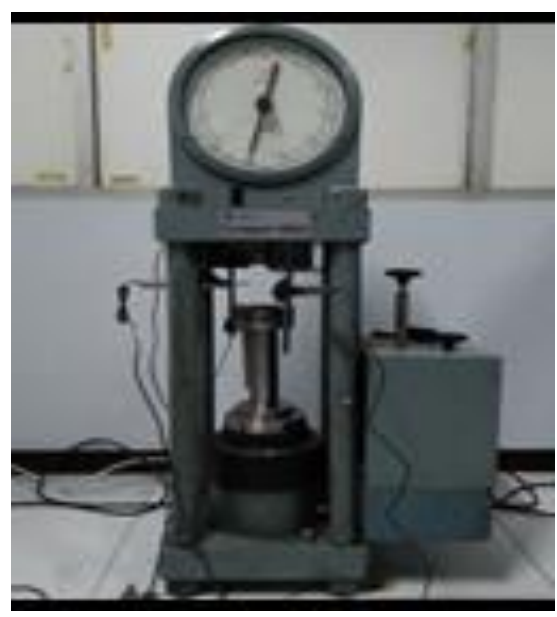

a. Alat uji kuat tekan (UCS)

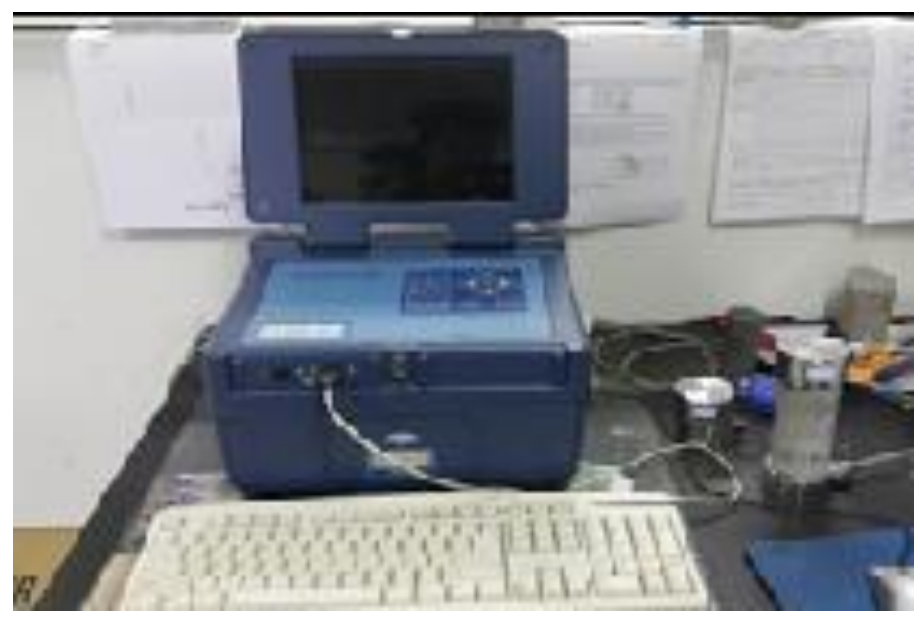

b. Alat uji ultrasonik

Gambar 3. Peralatan uji kuat tekan (a) dan ultrasonik (b) 
Tabel 2. Hasil pengujian dan perhitungan nilai UCS dan ultasonik pada batu lempung

\begin{tabular}{|c|c|c|c|c|c|c|c|c|c|}
\hline \multirow{3}{*}{ No } & \multirow{3}{*}{$\begin{array}{c}\text { Kode } \\
\text { percontoh }\end{array}$} & \multirow{3}{*}{$\begin{array}{l}\text { Kedalaman } \\
\qquad(\mathrm{m})\end{array}$} & \multicolumn{7}{|c|}{ Sifat-sifat Mekanik Batuan } \\
\hline & & & \multicolumn{3}{|c|}{ Uji UCS } & \multicolumn{4}{|c|}{ Uji Ultrasonik } \\
\hline & & & $\frac{\sigma \mathrm{c}}{\left(\mathrm{kg} / \mathrm{cm}^{2}\right)}$ & $\frac{E}{\left(\mathrm{~kg} / \mathrm{cm}^{2}\right)}$ & $\mu$ & $\frac{V p}{\text { (m/det) }}$ & $\frac{\mathrm{Vs}}{\text { (m/det) }}$ & $\begin{array}{c}\mathrm{E} \\
\left(\mathrm{kg} / \mathrm{cm}^{2}\right)\end{array}$ & $\mu$ \\
\hline 1 & UCG-CS1 & $21,26-21,94$ & 18,48 & 11296,29 & 0,30 & 1942,86 & 721,56 & 22859,82 & 0,42 \\
\hline 2 & UCG-CS2 & $26,68-27,68$ & 4,17 & 466,22 & 0,29 & 1021,92 & 490,91 & 9818,94 & 0,35 \\
\hline 3 & UCG-CS3 & $43,85-44,35$ & 116,56 & 14365,25 & 0,27 & 7719,23 & 3800,69 & 854786,93 & 0,34 \\
\hline 4 & UCG-CS4 & $43,85-44,35$ & 217,98 & 26704,90 & 0,12 & 13367,65 & 4030,50 & 1090131,28 & 0,45 \\
\hline 5 & UCG-CS5 & $85,77-86,77$ & 132,49 & 16857,46 & 0,22 & 9007,69 & 5489,06 & 1474804,26 & 0,20 \\
\hline 6 & UCG-CS6 & $94,00-94,60$ & 53,05 & 4816,15 & 0,46 & 1536,08 & 738,35 & 20968,80 & 0,35 \\
\hline 7 & UCG-CS7 & $138,80-138,90$ & 53,12 & 5432,22 & 0,37 & 1773,49 & 854,93 & 40701,06 & 0,35 \\
\hline 8 & UCG-CS8 & $144,59-144,92$ & 94,69 & 5246,60 & 0,31 & 7888,64 & 2916,81 & 305265,04 & 0,42 \\
\hline 9 & UCG-CS9 & $219,15-219,70$ & 69,32 & 6655,38 & 0,42 & 4083,43 & 1860,94 & 203521,65 & 0,37 \\
\hline 10 & GT - 8J & $111,00-111,60$ & 52,67 & 5579,20 & 0,33 & 2305,17 & 828,72 & 39743,44 & 0,43 \\
\hline 11 & GT - 8K & 5,98 & 29,24 & 2260,83 & 0,29 & 1487,80 & 701,15 & 27145,64 & 0,36 \\
\hline 12 & GT - 8L & $123,28-123,82$ & 26,64 & 2095,39 & 0,27 & 1910,94 & 694,89 & 29231,40 & 0,42 \\
\hline 13 & GT - 8M & $138,47-138,94$ & 43,06 & 3867,87 & 0,28 & 1980,30 & 848,70 & 44531,12 & 0,39 \\
\hline 14 & GT - 8N & $144,00-144,65$ & 51,67 & 4560,17 & 0,30 & 1999,48 & 778,92 & 35639,33 & 0,41 \\
\hline 15 & GT - $8 U$ & $243,52-244,00$ & 12,59 & 658,89 & 0,27 & 1457,45 & 666,13 & 25381,24 & 0,37 \\
\hline 16 & GT - 8W & - 249,47 & 12,19 & 839,16 & 0,28 & 1386,43 & 431,33 & 12014,16 & 0,45 \\
\hline 17 & GT - 8Y & $258,53-258,94$ & 5,59 & 406,83 & 0,29 & 1303,06 & 552,02 & 17230,02 & 0,39 \\
\hline 18 & GT $-8 A B$ & $268,00-268,40$ & 36,74 & 4204,07 & 0,27 & 1547,24 & 655,00 & 25196,66 & 0,39 \\
\hline 19 & GT - 8AD & $277,20-277,60$ & 49,86 & 4776,94 & 0,33 & 2223,53 & 883,18 & 50418,37 & 0,41 \\
\hline 20 & GT - 9A & $24,15-24,65$ & 6,98 & 1082,95 & 0,26 & 1509,02 & 510,69 & 15139,94 & 0,44 \\
\hline 21 & GT - 9E & $62,85-62,90$ & 3,39 & 236,03 & 0,24 & 1100,00 & 524,64 & 15095,94 & 0,35 \\
\hline 22 & GT - 9l & $91,28-91,71$ & 49,05 & 5237,06 & 0,30 & 1266,53 & 747,86 & 29990,32 & 0,23 \\
\hline 23 & GT - 9L & $104,15-104,82$ & 25,77 & 2889,73 & 0,30 & $\mathbf{9 7 7 , 3 6}$ & 411,66 & 10025,63 & 0,39 \\
\hline 24 & GT - 9P & $14,59-144,92$ & 58,79 & 6824,11 & 0,33 & 2098,91 & 828,57 & 40111,16 & 0,41 \\
\hline 25 & GT - 9R & $150,15-150,75$ & 41,61 & 6995,52 & 0,30 & 1387,22 & 615,00 & 21562,93 & 0,38 \\
\hline 26 & GT - 9AB & $214,49-215,15$ & 43,01 & 4303,18 & 0,29 & 1948,85 & 670,77 & 27206,32 & 0,43 \\
\hline 27 & GT - 9AD & $219,15-219,70$ & 50,42 & 5647,62 & 0,31 & 2051,72 & 908,40 & 50335,06 & 0,38 \\
\hline
\end{tabular}

Tabel 3. Hasil pengujian dan perhitungan nilai UCS dan ultasonik pada batu napal

\begin{tabular}{|c|c|c|c|c|c|c|c|c|c|}
\hline \multirow{4}{*}{ No } & \multirow{4}{*}{$\begin{array}{c}\text { Kode } \\
\text { Percontoh }\end{array}$} & \multirow{4}{*}{$\begin{array}{l}\text { Kedalaman } \\
\qquad(\mathrm{m})\end{array}$} & \multicolumn{7}{|c|}{ Sifat-sifat Mekanik Batuan } \\
\hline & & & \multicolumn{3}{|c|}{ Uji UCS } & \multicolumn{4}{|c|}{ Uji Ultrasonik } \\
\hline & & & $\sigma \mathrm{c}$ & $\mathrm{E}$ & & $V p$ & Vs & $E$ & \\
\hline & & & $\left(\mathrm{kg} / \mathrm{cm}^{2}\right)$ & $\left(\mathrm{kg} / \mathrm{cm}^{2}\right)$ & $\mu$ & $(\mathrm{m} / \mathrm{det})$ & $(\mathrm{m} / \mathrm{det})$ & $\left(\mathrm{kg} / \mathrm{cm}^{2}\right)$ & $\mu$ \\
\hline 1 & UCG-NS1 & $18,40-18,90$ & 276,45 & 54250,84 & 0,11 & 7920,16 & 4689,97 & 1107627,93 & 0,23 \\
\hline 2 & UCG-NS2 & $19,48-19,95$ & 9,10 & 342,29 & 0,30 & 948,00 & 402,57 & 8384,37 & 0,39 \\
\hline 3 & UCG-NS3 & $19,48-19,95$ & 35,48 & 5784,32 & 0,29 & 4196,70 & 1480,23 & 157611,45 & 0,43 \\
\hline 4 & UCG-NS4 & $20,40-20,90$ & 31,10 & 2454,05 & 0,23 & 2324,05 & 1147,50 & 79592,81 & 0,34 \\
\hline 5 & UCG-NS5 & $20,40-20,90$ & 41,06 & 8513,22 & 0,28 & 2062,29 & 1037,07 & 64837,11 & 0,33 \\
\hline 6 & UCG-NS6 & $30,40-30,90$ & 51,97 & 7137,98 & 0,29 & 4546,55 & 1801,69 & 171611,02 & 0,40 \\
\hline 7 & UCG-NS7 & $40,20-40,70$ & 219,50 & 17809,98 & 0,22 & 7518,75 & 2506,25 & 421576,65 & 0,44 \\
\hline 8 & UCG-NS8 & $46,90-47,40$ & 151,58 & 97760,86 & 0,23 & 3285,85 & 1393,20 & 134696,57 & 0,39 \\
\hline 9 & UCG-NS9 & $50,90-51,40$ & 297,88 & 87908,29 & 0,27 & 8722,22 & 2855,02 & 550494,05 & 0,44 \\
\hline 10 & UCG-NSO & $70,40-70,90$ & 262,98 & 27183,45 & 0,34 & 6926,83 & 3563,82 & 730288,49 & 0,32 \\
\hline 11 & GT - 8C & $19,48-19,95$ & 9,38 & 999,29 & 0,30 & 1123,15 & 525,11 & 15840,77 & 0,36 \\
\hline 12 & GT - 8D-1 & $21,26-21,94$ & 7,60 & 331,01 & 0,28 & 861,85 & 351,85 & 6766,28 & 0,40 \\
\hline 13 & GT - 8AG & $69,00-69,57$ & 13,69 & 1046,01 & 0,27 & 1135,09 & 459,95 & 11723,01 & 0,40 \\
\hline 14 & GT - 8H & $102,24-104,67$ & 15,66 & 3074,68 & 0,29 & 1827,42 & 674,40 & 26426,16 & 0,42 \\
\hline 15 & GT - $8 \mathrm{O}$ & $197,00-197,65$ & 63,07 & 4925,44 & 0,30 & 1628,57 & 770,27 & 34458,82 & 0,36 \\
\hline 16 & GT - 8Q & $216,35-216,92$ & 16,30 & 1295,43 & 0,30 & 1062,73 & 389,67 & 8819,17 & 0,42 \\
\hline 17 & GT - 8T & $240,03-241,00$ & 9,82 & 338,77 & 0,28 & 1014,97 & 376,67 & 8505,95 & 0,42 \\
\hline 18 & GT - 9C & $37,25-37,75$ & 17,73 & 1149,00 & 0,29 & 1548,39 & 709,80 & 27096,24 & 0,37 \\
\hline 19 & GT $-9 \mathrm{H}$ & $90,15-90,23$ & 57,53 & 5759,84 & 0,32 & 1366,15 & 754,14 & 31879,83 & 0,28 \\
\hline 20 & GT - 9K & $96,40-97,00$ & 24,37 & 2209,62 & 0,30 & 1327,87 & 458,92 & 11955,10 & 0,43 \\
\hline 21 & GT - 9U & $158,79-159,15$ & 10,17 & 3963,55 & 0,28 & 2119,78 & 652,17 & 29242,23 & 0,45 \\
\hline 22 & GT - 9W-1 & $164,15-164,65$ & 13,91 & 799,82 & 0,28 & 1123,15 & 510,20 & 14314,50 & 0,37 \\
\hline 23 & GT - 9Y & $173,15-173,55$ & 22,99 & 3533,20 & 0,30 & 1389,71 & 720,00 & 29555,85 & 0,32 \\
\hline 24 & GT - 9L & $104,15-104,82$ & 25,77 & 2889,73 & 0,30 & 977,36 & 411,66 & 10025,63 & 0,39 \\
\hline 25 & GT - 9AB & $214,49-215,15$ & 43,01 & 4303,18 & 0,29 & 1948,85 & 670,77 & 27206,32 & 0,43 \\
\hline
\end{tabular}


Prediksi Nilai Kuat Tekan Uniaksial Batuan Pengapit Batubara Menggunakan Data ... Zulfahmi dkk.

Tabel 4. Hasil Pengujian dan Perhitungan nilai UCS dan Ultasonik pada batu pasir

\begin{tabular}{|c|c|c|c|c|c|c|c|c|c|}
\hline \multirow{4}{*}{ No } & \multirow{4}{*}{$\begin{array}{c}\text { Kode } \\
\text { percontoh }\end{array}$} & \multirow{4}{*}{$\begin{array}{l}\text { kedalaman } \\
\qquad(\mathrm{m})\end{array}$} & \multicolumn{7}{|c|}{ Sifat-sifat Mekanik Batuan } \\
\hline & & & \multicolumn{3}{|c|}{ Uji UCS } & \multicolumn{4}{|c|}{ Uji Ultrasonik } \\
\hline & & & $\sigma \mathrm{C}$ & $E$ & & $V p$ & Vs & $E$ & \\
\hline & & & $\left(\mathrm{kg} / \mathrm{cm}^{2}\right)$ & $\left(\mathrm{kg} / \mathrm{cm}^{2}\right)$ & $\mu$ & $(\mathrm{m} / \mathrm{det})$ & (m/det) & $\left(\mathrm{kg} / \mathrm{cm}^{2}\right)$ & $\mu$ \\
\hline 1 & UCG-PS1 & $40,15-40,70$ & 11,41 & 2900,71 & 0,21 & 1325,27 & 514,54 & 12645,00 & 0,41 \\
\hline 2 & UCG-PS2 & $68,90-69,40$ & 271,33 & 20849,83 & 0,13 & 7120,00 & 2780,84 & 490225,50 & 0,41 \\
\hline 3 & UCG-PS3 & $68,90-69,40$ & 21,22 & 618,36 & 0,09 & 1647,59 & 611,90 & 17534,74 & 0,42 \\
\hline 4 & UCG-PS4 & $68,90-69,40$ & 20,51 & 697,91 & 0,16 & 1595,65 & 837,32 & 29518,68 & 0,31 \\
\hline 5 & UCG-PS5 & $94,40-94,80$ & 28,20 & 1005,70 & 0,19 & 2272,13 & 1307,55 & 62618,94 & 0,25 \\
\hline 6 & UCG-PS6 & $112,60-133,60$ & 7,07 & 1775,07 & 0,37 & 3606,19 & 1507,76 & 124077,57 & 0,39 \\
\hline 7 & UCG-PS7 & $197,00-197,40$ & 22,28 & 813,89 & 0,24 & 1684,21 & 883,79 & 28158,97 & 0,31 \\
\hline 8 & UCG-PS8 & $218,40-218,87$ & 16,46 & 1776,55 & 0,50 & 2145,35 & 1030,73 & 60051,56 & 0,35 \\
\hline 9 & UCG-PS9 & $218,40-218,87$ & 219,75 & 24774,39 & 0,38 & 4331,71 & 1909,68 & 228828,00 & 0,38 \\
\hline 10 & GT - 8A & $9,40-10,00$ & 86,43 & 7409,01 & 0,27 & 1686,79 & 777,39 & 30689,84 & 0,37 \\
\hline 11 & GT - 8B & $14,26-14,85$ & 11,63 & 1767,11 & 0,29 & 1540,21 & 776,10 & 28566,11 & 0,33 \\
\hline 12 & GT - 8KF & $93,00-93,58$ & 66,93 & 8538,57 & 0,33 & 2379,63 & 1095,17 & 69713,09 & 0,37 \\
\hline 13 & GT - 8I & $108,32-108,79$ & 14,63 & 1116,01 & 0,28 & 1239,08 & 453,48 & 11346,87 & 0,42 \\
\hline 14 & GT - 8R & $218,40-218,87$ & 17,58 & 981,84 & 0,32 & 1186,54 & 411,33 & 10215,63 & 0,43 \\
\hline 15 & GT - 8S & $228,38-228,80$ & 14,74 & 803,98 & 0,26 & 1011,63 & 377,17 & 8183,83 & 0,42 \\
\hline 16 & GT - 8YZ & $260,00-260,53$ & 52,00 & 6471,22 & 0,33 & 1801,40 & 973,45 & 55854,95 & 0,29 \\
\hline 17 & GT - 8AA & $264,38-264,78$ & 9,88 & 762,92 & 0,26 & 1280,60 & 472,73 & 13408,04 & 0,42 \\
\hline 18 & GT - 8AE & $335,00-335,49$ & 35,43 & 6098,08 & 0,32 & 1533,78 & 790,02 & 34530,68 & 0,32 \\
\hline 19 & GT - 8AF & $345,00-345,49$ & 87,08 & 7860,43 & 0,27 & 1821,43 & 1022,73 & 59236,28 & 0,27 \\
\hline 20 & GT - 9B1 & $33,25-33,85$ & 4,90 & 341,26 & 0,25 & 926,35 & 378,18 & 6951,95 & 0,40 \\
\hline 21 & GT - 9D1 & $40,15-40,70$ & 9,67 & 479,94 & 0,26 & 1033,00 & 508,61 & 13338,79 & 0,34 \\
\hline 22 & GT - 9F & $67,15-67,57$ & 13,79 & 1502,84 & 0,29 & 1615,38 & 598,10 & 20224,06 & 0,42 \\
\hline 23 & GT - 9G & $71,15-71,45$ & 9,94 & 695,12 & 0,27 & 1419,32 & 600,48 & 19881,37 & 0,39 \\
\hline 24 & GT - 9J1 & $94,40-94,80$ & 13,95 & 942,64 & 0,27 & 1264,55 & 556,33 & 16973,39 & 0,38 \\
\hline 25 & GT - 9M & $110,15-110,71$ & 13,09 & 737,21 & 0,29 & 1244,90 & 352,60 & 7257,96 & 0,46 \\
\hline 26 & GT - 9N & $112,60-113,60$ & 7,64 & 302,23 & 0,28 & 759,74 & 485,71 & 8104,28 & 0,33 \\
\hline 27 & GT - 901 & $115,15-115,58$ & 448,04 & 36130,61 & 0,34 & 51130,93 & 25175,13 & 41206813 & 0,34 \\
\hline 28 & GT - 9Q & $147,15-147,74$ & 6,89 & 3051,42 & 0,24 & 1428,57 & 666,67 & 25052,53 & 0,36 \\
\hline 29 & GT - 9S & $155,15-155,58$ & 8,49 & 769,14 & 0,26 & 1425,57 & 781,25 & 32442,01 & 0,29 \\
\hline 30 & GT - 9V & $163,23-163,68$ & 12,92 & 764,44 & 0,24 & 1033,90 & 362,02 & 7793,36 & 0,43 \\
\hline 31 & GT - 9X & $171,75-172,15$ & 26,01 & 2191,96 & 0,27 & 1783,41 & 579,34 & 19629,48 & 0,44 \\
\hline 32 & GT - 9Z & $177,15-177,57$ & 26,44 & 2863,53 & 0,28 & 1508,24 & 497,28 & 16054,44 & 0,44 \\
\hline 33 & GT - 9AC & $216,15-216,70$ & 49,80 & 6060,24 & 0,30 & 2038,26 & 965,93 & 55994,68 & 0,36 \\
\hline 34 & GT - 9AE & $279,30-279,78$ & 55,04 & 5549,86 & 0,31 & 1727,03 & 868,21 & 42315,04 & 0,33 \\
\hline 35 & GT - 9AF & $287,69-288,15$ & 77,81 & 10943,24 & 0,33 & 1549,14 & 764,68 & 34098,74 & 0,34 \\
\hline 36 & GT - 9L & $104,15-104,82$ & 25,77 & 2889,73 & 0,3 & 977,36 & 411,66 & 10025,63 & 0,39 \\
\hline 37 & GT - 9AB & $214,49-215,15$ & 43,01 & 4303,18 & 0,29 & 1948,85 & 670,77 & 27206,32 & 0,43 \\
\hline
\end{tabular}

Dengan melakukan korelasi antara nilai $\sigma_{c}$ hasil uji UCS dan $V_{p}$ hasil uji ultrasonik diperoleh nilai persamaan polinomial seperti ditunjukkan pada Gambar 3, 4 dan 5.

Dengan melihat nilai coefficient of determination $\left(R^{2}\right)$ yang cukup tinggi dari hasil korelasi antara uji UCS dan ultrasonik dari ketiga batu lempung, batu lanau dan batu pasir yaitu di atas 85\%, maka secara empiris nilai kedua uji ini cukup meyakinkan untuk dijadikan data awal atau data empiris untuk menentukan salah satu nilai dari kedua pengujian ini. Artinya apabila telah dilakukan uji ultrasonik, maka secara empiris dapat ditentukan nilai UCS dari batuan tersebut. 


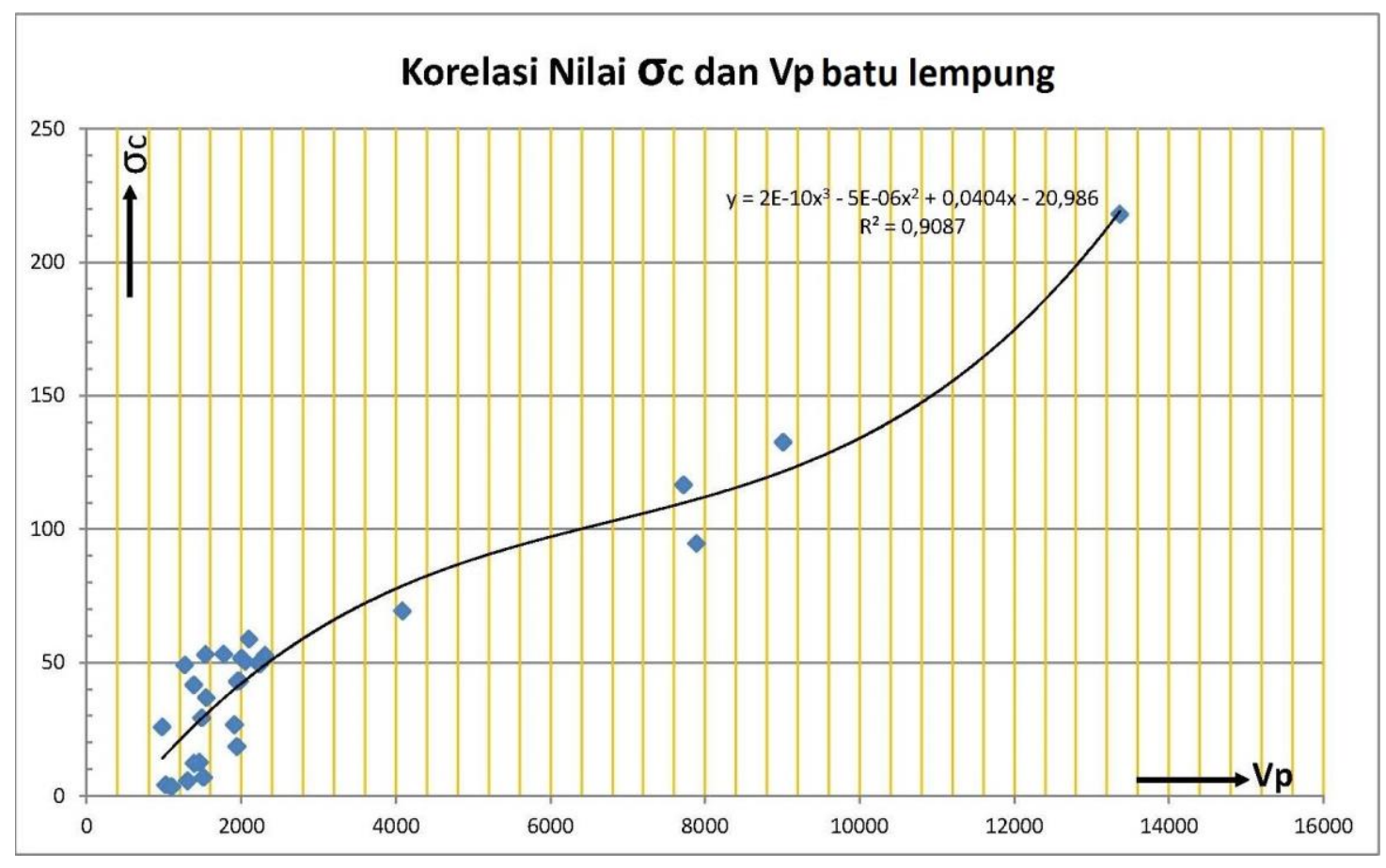

Gambar 3. Korelasi nilai oc (uji UCS) dan nilai kecepatan rambat gelombang $\mathrm{P}$ (uji ultrasonik) pada batu lempung

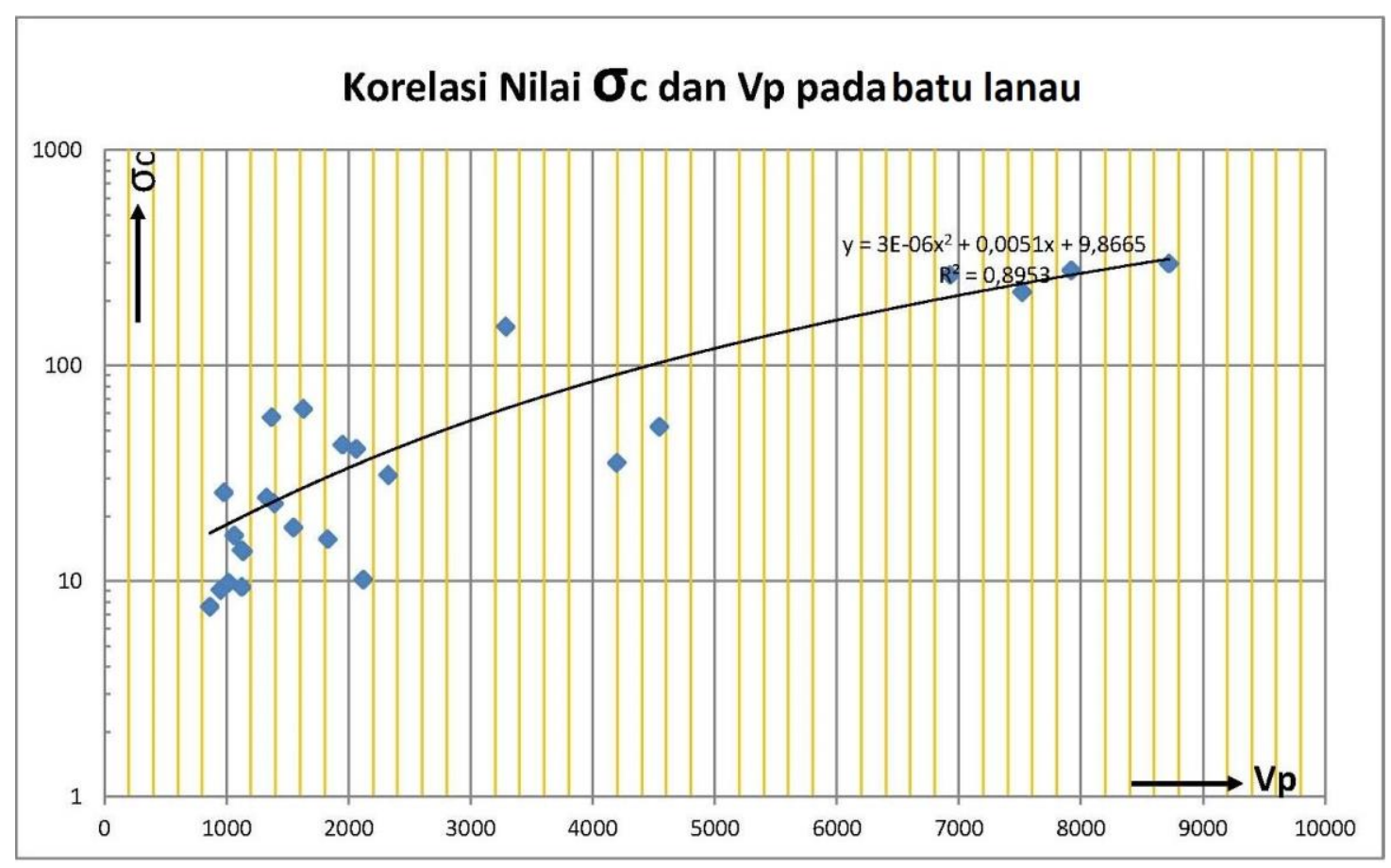

Gambar 4. Korelasi nilai oc (uji UCS) dan nilai kecepatan rambat gelombang $\mathrm{P}$ (uji ultrasonik) pada batu lanau 


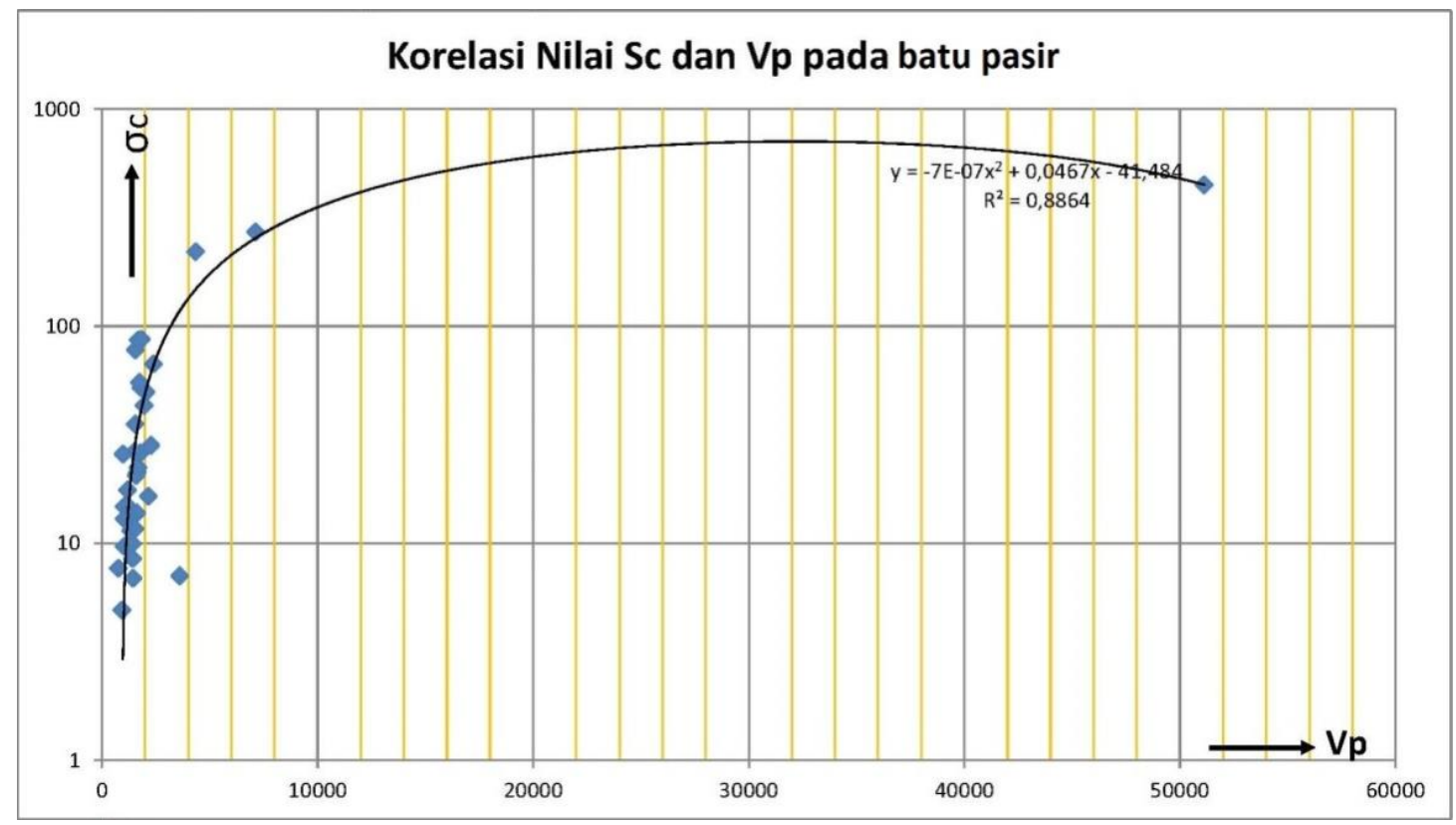

Gambar 5. Korelasi nilai $\sigma c$ (uji UCS) dan nilai kecepatan rambat gelombang P (uji ultrasonik) pada batu pasir

\section{KESIMPULAN DAN SARAN}

Telah diperoleh tiga korelasi empiris untuk tiga jenis batuan pengapit batubara di lokasi telitian di desa Macang Sakti, Kecamatan Sangadesa, Kabupaten Musi Banyuasin, Propoinsi Sumatera Selatan yaitu batu lempung, batu lanau dan batu pasir. Korelasi ini dapat digunakan untuk memprediksi nilai UCS dari hasil uji ultrasonik. Pengujian dengan ultrasonik sangat mudah, tidak merusak percontoh batuan dan dapat digunakan untuk pengujian lain, sehingga penggunaan percontoh dapat lebih optimal. Korelasi empiris untuk ketiga batuan tersebut diperoleh dari persamaan polinomial ordo 2 dan ordo 3, yaitu untuk Claystone nilai $\sigma_{c}$ dapat diperoleh dari UCS $\mathrm{Cls}_{\mathrm{s}}=\left(2 \times 10^{-10}\right) \mathrm{Vp}^{3}$ $\left(5 \times 10^{-6}\right) V_{p}^{2}+0,0404 V_{p}-20,986$ dengan nilai $R^{2}=0,9087$. Untuk Siltstone nilai $\sigma_{c}$ dapat diperoleh $\mathrm{UCS}_{\text {sis }}=\left(3 \times 10^{-6}\right) \mathrm{V}_{\mathrm{p}}{ }^{2}+$ $0,0051 V_{p}+9,8665$ dengan nilai $R^{2}=$ 0,8953 dan nilai $\sigma c S a n d s t o n e$ dapat diperoleh dari $\mathrm{UCS}_{\mathrm{sas}}=-\left(7 \times 10^{-7}\right) \mathrm{V}_{\mathrm{p}}{ }^{2}+$ $0,0467 V_{p}-41,484$ dengan nilai $R^{2}=0,8864$.

\section{UCAPAN TERIMA KASIH}

Kegiatan penelitian ini dibiayai oleh anggaran kegiatan penelitian Puslitbang
Teknologi Mineral dan Batubara (tekMIRA) yang berada di lokasi PT. Astaka Dodol. Terima kasih disampaikan kepada manajemen tekMIRA dan PT. Astaka Dodol yang telah memberikan kesempatan kepada penulis untuk melakukan penelitian ini. Terimakasih juga disampaikan kepada tim aplikasi teknologi UCG baik yang melaksanakan kegiatan lapangan maupun kegiatan administratif, sehingga terkumpul data yang tak ternilai harganya ini.

\section{DAFTAR PUSTAKA}

Ali, B. A. H. (2008) Assessment of concrete compressive strength by ultrasonic nondestructive test. University of Baghdad.

Asian Pacific Economy Cooperation (2013) APEC energy demand and outlook 5th edition.

Badan Standardisasi Nasional (1991) SNI 03-24851991: Benda uji batu, metode pengujian laboratorium cepat rambat ultrasonik dan konstanta elastis.

Badan Standardisasi Nasional (2008) SNI 2825:2008: Cara uji kuat tekan batu uniaksial. Indonesia.

Barton, N. (2002) "Some new Q-value correlations to assist in site characterisation and tunnel 
design," International Journal of Rock Mechanics and Mining Sciences, 39(2), hal. 185-216. doi: 10.1016/S13651609(02)00011-4.

Briševac, Z., Hrženjak, P. dan Buljan, R. (2015) "Models for estimating uniaxial compressive strength and elastic modulus," GRAĐEVINAR, 68(1), hal. 19-28. doi: 10.14256/JCE.1431.2015.

Chang, C., Zoback, M. dan Khaksar, A. (2006) "Empirical relations between rock strength and physical properties in sedimentary rocks," Journal of Petroleum Science and Engineering, 51(3-4), hal. 223-237. doi: 10.1016/j.petrol.2006.01.003.

De Coster, G. L. (1974) "The geology of central and South Sumetra basin," in Proceedings Indonesian Petroleum Association. 3rd Annual Convention. Jakarta: Indonesian Petroleum Association, hal. 77-110.

Horsrud, P. (2001) "Estimating mechanical properties of shale from empirical correlations," Society of petroleum engineers, SPE 56017(June), hal. 68-73. doi: 10.2118/56017-PA.

Kabilan, N., Muttharam, M., Siva, A. dan Philips, N. (2016) "Prediction of uniaxial compressive strength using point load index for jointed rocks," IOSR Journal of Mechanical and Civil Engineering, 13(3), hal. 1-7.

Karaman, K., Cihangir, F., Ercikdi, B., Kesimal, A. dan Demirel, S. (2015) "Utilization of the Brazilian test for estimating the uniaxial compressive strength and shear strength parameters," Journal of the Southern African Institute of Mining and Metallurgy, 115(3), hal. 185-192.

Lai, G. T., Rafek, A. G., Serasa, A. S., Hussin, A. dan Lee, K. E. (2016) "Use of ultrasonic velocity travel time to estimate uniaxial compressive strength of granite and schist in Malaysia," Use of Ultrasonic Velocity Travel
Time to Estimate Uniaxial Compressive Strength of Granite and Schist in Malaysia, 45(2), hal. 185-193.

Lai, G. T., Rafek, A. G., Serasa, A. S., Simon, N. dan Lee, K. E. (2014) "Empirical correlation of uniaxial compressive strength and primary wave velocity of Malaysian granites," 19(Bund. E), hal. 1064-1072.

Martinez-Martinez, J., Benavente, D., Cura, M. a G. D. E. L. dan Canaveras, J. . (2006) Application of ultrasonics to brecciated dolostones for assessing their mechanical properties, IAEG. 243.

McNally, G. H. (1987) "Estimation of coal measures rock strength using sonic and neutron logs," Geoexploration, 24(4-5), hal. 381-395. doi: 10.1016/00167142(87)90008-1.

Minjbouw, S. N. V. (1978) Explanatory notes to the geological map of the South Sumatran coal Province.

Pusat Sumber Daya Geologi (2012) Neraca energi fossil tahun 2011. Bandung.

Rao, S. K., Sravana, P. dan Rao, T. C. (2016) "Relationship between ultrasonic pulse velocity and compressive strength for roller compacted concrete containing GGBS," International Journal of Applied Engineering Research, 11(3), hal. 2077-2084.

Sugiyono, A., Permana, A. D., Boedoyo, M. S. dan Adiarso (2013) Outlook energi Indonesia 2013. Diedit oleh A. Sugiyono, A. D. Permana, M. S. Boedoyo, dan Adiarso. Jakarta: Badan Pengkajian dan Penerapan Teknologi.

Yurdakul, M., Ceylan, H. dan Akdas, H. (2011) “A predictive model for uniaxial compressive strength of carbonate rocks from Schmidt hardness," American Rock Mechanics Association, 11-533, hal. American Rock Mechanics Association (ARMA). 